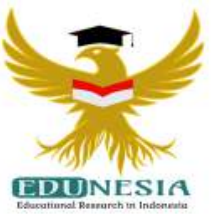

\title{
Struktur Puisi Karya John Dami Mukese Serta Relevansinya Dalam Pembelajaran Sastra
}

\author{
Rosa Dalima Bunga'; Hawiah Djumadin²; Maria Magdalena Rini ${ }^{3}$ \\ 1,2,3Pendidikan Bahasa dan Sastra Indonesia, Universitas Flores, Indonesia. \\ 1Corresponding Email: dalimarisma@gmail.com , Phone Number : 0852 xxxx xxxx
}

\author{
Article History: \\ Received: Juli 24, 2020 \\ Revised: Agust 21, 2020 \\ Accepted: Agust 21, 2020 \\ Published: Jan 01, 2021
}

\section{Keywords: \\ Learning, \\ Literature, \\ Poetry structure.}

\section{Kata Kunci:}

Pembelajaran,

Sastra,

Struktur puisi.

\section{How to cite:}

Bunga,R.D., Djumadin.H., \& Rini,M.M. (2021). Struktur Puisi Karya John Dami Mukese Serta Relevansinya Dalam Pembelajaran Sastra. Edunesia : Jurnal Ilmiah Pendidikan, 2 (1): 1-9,

This is an open access article under the CC-BY-NC-ND license

\begin{abstract}
This study aims to describe the structure of the poem "Autumn" by John Dami Mukese which consists of physical and inner structures and their relevance to the study of literature in high school. This study uses a qualitative approach with qualitative descriptive methods. The data in this study are in the form of words that contain physical and inner structure in the poem "Autumn" by John Dami Mukese. The data source is a collection of books "Jelata Poel Jelata" by John Dami Mukese. Data collection procedures in this study are reading, identifying, modifying, and classifying in accordance with the focus of the study. Data analysis uses in-depth understanding techniques. Checking the validity of the data is done through triangulation techniques. The results of the poem builder research structure consisting of physical structures in the form of: connotative and denotative diction; visual imaging; concrete words; style of personification and repetition; rhyme; and typography. The inner structure of themes; feeling (taste); tone; and mandate. The structure of the builders of "Autumn" poetry by John Dami Mukese can be used as teaching material in the study of literature in high school specifically at KD 3.17 analyzing the elements of poetry builders.
\end{abstract}

Abstrak: Penelitian ini bertujuan untuk mendeskripsikan struktur puisi "Musim Gugur" karya John Dami Mukese yang terdiri atas struktur fisik dan struktur batin dan relevansinya dengan pembelajaran sastra di SMA. Penelitian ini menggunakan pendekatan kualitatif dengan metode deskriptif kualitatif. Data dalam penelitian ini berupa kata-kata yang mengandung struktur fisik dan batin dalam puisi "Musim Gugur" karya John Dami Mukese. Sumber data adalah buku kumpulan "Puisi-Puisi Jelata" karya John Dami Mukese. Prosedur pengumpulan data dalam penelitian ini adalah membaca, mengidentifikasi, mengodifikasi, dan mengklasifikasikan sesuai dengan fokus penelitian. Analisis data menggunakan teknik pemahaman arti secara mendalam. Pengecekan keabsahan data dilakukan melalui teknik triangulasi. Hasil penelitian struktur pembangun puisi yang terdiri atas struktur fisik berupa: diksi konotatif dan denotatif; pengimajian visual; kata konkret; gaya bahasa personifikasi dan repetisi; rima; dan tipografi. Struktur batin berupa tema; feeling (rasa); nada; dan amanat. Struktur pembangun puisi "Musim Gugur" karya John Dami Mukese dapat digunakan sebagai bahan ajar dalam pembelajaran sastra di SMA secara khusus pada KD 3.17 menganalisis unsur pembangun puisi. 


\section{A. Pendahuluan}

Karya sastra juga merupakan gambaran dari segala hal yang ada di dunia yang oleh penulis diubah ke dalam karya sastra. Sedangkan, sastrawan itu sendiri adalah anggota masyarakat yang terikat status sosial tertentu dan tidak dapat mengelak dari adanya pengaruh yang diterimanya dari lingkungan yang membesarkan sekaligus membentuknya, Wiyatmi, (2012). Karya sastra memiliki peran yang sangat penting dalam masyarakat karena karya sastra merupakan refleksi atau cerminan kondisi sosial masyarakat yang terjadi di dunia sehingga karya itu menggugah perasaan orang untuk berpikir tentang kehidupan. Masalah sosial dan kejadian yang dialami, dirasakan dan dilihat oleh pengarang kemudian melahirkan ide atau gagasan yang dituangkan dalam karyanya.

Sebuah karya sastra memiliki daya gugah terhadap batin dan jiwa seseorang. Selain itu juga, karya sastra merupakan media untuk mengutarakan sisi-sisi kehidupan manusia dan memuat kebenaran-kebenaran kehidupan manusia yang kadang-kadang kebenaran itu bersifat sejarah. Di antara genre besar sastra yaitu prosa, puisi, dan drama, yang memuat pokok apresiasif kesusastraan khususnya dalam prinsip otonomi sastra yang kompleks adalah puisi, sebab puisi merupakan lukisan kata-kata tertentu yang menghasilkan dunianya yang baru, yakni dunia teks.

Keberadaan puisi sebagai bentuk cipta sastra, tidaklah lahir begitu saja. Puisi lahir dan diciptakan oleh penyairnya melalui proses tertentu. Proses tersebut, mungkin saja sama antara penyair yang satu dengan penyair yang lain, atau mungkin juga berbeda. Hal itu harus disadari, mengingat setiap penyair memiliki pandangan-pandangan yang berbeda, serta pengetahuan dan pengalaman yang berbeda pula. Akan tetapi suatu hal yang tidak dapat dipungkiri adalah puisi itu lahir dan diciptakan oleh penyairnya dengan bersumber pada pengetahuan, pengalaman, dan pandangan yang dimilikinya.

Puisi yang diciptakan merupakan bentuk kesaksian penyair terhadap peristiwa maupun objek yang terdapat dalam kehidupan. Agar puisi yang dinikmati oleh penikmat sastra memiliki kesan tersendiri tentunya penyair harus memilih bahasa yang indah. Bahasa-bahasa tersebut dapat dilihat dalam struktur puisi secara khusus puisi "Musim Gugur" karya John Dami Mukese. John Dami mukese secara naional mendapat pengakuan sebagai penyair ketika sepuluh puisi pilihan dari kumpulan puisi berjudul "Doa-Doa Semesta" ikut menyemarakan halaman-halaman TONGGAK, Antologi Puisi Indonesia Modern 4 yang diedit oleh Linus Suryadi A.G (Wisang, 2014). Selain itu nama penyair John Dami Mukese mulai dikenal di panggung sastra nasional Indonesia tatkala puisi panjangnya berjudul "Doa-Doa Semesta" dimuat dalam majalah sastra Horison pada edisi Nomor 2, Tahun 1983, halaman 86-89. Puisi ini ditulisnya selama dua bulan, JuliAgustus 1982 di Biara Santu Yosef, Ende. Dialah orang NTT pertama yang karyanya bisa tembus majalah sastra Horison meskipun tinggal dan berkarya di daerah Flores, (Sehandi, 2018).

Untuk mengangkat sastrawan Nusa Tenggara Timur (NTT) dan juga karya sastra yang dihasilkan secara khusus penyair, John Dami Mukese yang telah meninggal pada 26 Oktober 2017 melalui pembelajaran sastra. Sehingga para guru Bahasa Indonesia dapat memanfaatkan hasil penelitian ini sebagai salah satu contoh materi pembelajaran tentang unsur pembangun puisi di jenjang SMA yang terdapat pada KD 3. 17. Dalam pembelajaran guru hanya menggunakan puisi yang ada di dalam buku ajar atau puisipuisi karya pengarang Indonesia ternama yang mana karyanya sudah dianalisis secara berulang. Selain itu Sayuti dalam Nurhuda, dkk (2017) menyatakan bahwa apresiasi sastra 
pada masyarakat Indonesia masih sangat rendah. Guru cenderung menggunakan teknik pembelajaran yang berisi teori dan hafalan sehingga kegiatan pembelajaran berlangsung kaku, monoton, dan membosankan.

Dalam mengkaji sebuah puisi, unsur bahasa yang bertindak sebagai medium harus menjadi perhatian utama. Hal ini kaerna puisi merupakan peristiwa bahasa. Bahasa yang digunakan dalam puisi dapat dianalisis melalui struktur pembangun puisi yang terdiri atas struktur fisik dan struktur batin. Wisang (2014) membagi unsur pembangun puisi terdiri atas struk fisik atau struktur lahir terdiri atas: diksi; citraan; kata konkret; bahasa bermajas; irama dan rima; dan tipografi dan struktur bathin atau isi terdiri atas: tema; feeling (rasa); nada; dan amanat. Fokus penelitian ini adalah mengkaji unsur struktur pusi "Musim Gugur" karya John Dami Mukese dan relevansinya dengan pembelajaan sastra di SMA.

Penelitian terdahulu yang dianggap relevan dengan penelitian ini yakni penelitian yang dilakukan oleh Hamid \& Dede (2019) dengan judul "Kajian Puisi dan Pemanfaatannya sebagai Bahan Ajar Teks Puisi Berbasis Pendekatan Inkuiri". Penelitian tersebut bertujuan untuk membuat bahan ajar menulis teks puisi yang akan digunakan di SMA, khususnya di SMA Negeri I Sukahaji Kabupaten Majelengka. Menggunakan pendekatan kualitatif, dan untuk memperoleh data, menetapkan fokus penelitian, menafsirkan data, serta membuat kesimpulan atas temuannya menggunakan teori dari Sugiyono, yaitu dengan memilih dan menganalisis puisi-puisi yang dimuat pada majalah Horison. Hasil penelitian dari analisis struktur puisi-puisi yang terpilih pada majalah Horison dimanfaatkan untuk penyususnan bahan ajar menulis teks puisi yang akan digunakan di kelas X dengan KI dan KD dalam kurikulum 2013. Sedangkan tujuan penelitian yang dilakukan yakni mengkaji struktur fisik dan struktur batin puisi "Musim Gugur" karya John Dami Mukese serta relevansi dalam pembelajaran sastra di SMA pada KD 3.17 menganalisis unsur pembangun puisi.

\section{B. Metode}

Penelitian ini menggunakan pendekatan kualitatif dengan metode deskriptif kualitatif. Moleong (2013) mendefenisikan penelitian kualitatif adalah penelitian yang bermaksud untuk memahami fenomena tentang apa yang dialami oleh subjek penelitian. Data dalam penelitian ini berupa kata-kata yang mengandung struktur fisik dan batin dalam puisi "Musim Gugur" karya John Dami Mukese. Sumber data adalah buku kumpulan "Puisi-Puisi Jelata" karya John Dami Mukese. Prosedur pengumpulan data dalam penelitian ini adalah membaca, mengidentifikasi kata-kata dan kalimat dalam puisi "Musim Gugur" karya John Dami Mukese yang mengandung arti berdasarkan unsur fisik dan unsur batin , mengodifikasi kata-kata dan kalimat puisi "Musim Gugur" karya John Dami Mukese berdasarkan struktur fisik dan struktur batin, dan mengklasifikasikan katakata dan kalimat dalam puisi "Musim Gugur" karya John Dami Mukese sesuai dengan struktur fisik dan struktur batin. Analisis data menggunakan teknik pemahaman arti secara mendalam. Pengecekan keabsahan data dilakukan melalui teknik triangulasi. Triangulasi adalah teknik pemeriksaan kebasahan data yang memanfaatkan sesuatu yang lain, (Moleong, 2013). Triangulasi yang digunakan dalam penelitian ini adalah teman sejawat, dilakukan dengan diskusi bersama teman sejawat untuk memperkaya pegetahuan. 


\title{
C. Hasil dan Pembahasan
}

Pada bagian ini akan diuraikan hasil dan pembahasan tentang struktur puisi "Musim Gugur" karya John Dami Mukese dan relevansinya dalam pembelajaran sastra di SMA. Struktur puisi terdiri atas struktur fisik meliputi diksi; pengimajian; gaya bahasa; rima, dan tipografi sedangkan struktur batin meliputi tema; rasa, nada; dan amanat.

\author{
Struktur Fisik Puisi \\ "Musim Gugur" Karya John Dami Mukese \\ Ketapang depan kamarku kian meranggas \\ Daun-daunnya gugur menjamak \\ Langit pun makin kosong \\ ketika awan gugur dalam gosong \\ Musim gugur sudah tiba \\ Mempelam di rimba selatan \\ Satu-satunya menyatu bumi \\ Jutaan bayi tak genap usia \\ Ramai-ramai berganti rahim \\ Wahai musim gugur! \\ Kapankah kau berganti semi? \\ Bumi ini makin merah \\ oleh darah tak bersalah \\ akibat dosa tak kenal tobat
}

Ende, Mei 1982

\section{Diksi}

Diksi adalah pilihan kata, baik dalam penulisan bentuk puisi dan prosa maupun drama. Dalam pengetahuan umum diksi juga digunakan dalam penulisan ilmu pengetahuan, bahkan juga dalam kehidupan sehari-hari, Ratna (2013). Dalam karya sastra diksi digunakan untuk membangkitkan imajinasi pembaca, sehingga segala sesuatu yang diungkapkan sekaligus melahirkan manfaat dan nikmat.

Baris pertama Ketapang depan kamarku kian meranggas/ ketapang adalah salah satu jenis pepohonan, kamar adalah sebuah ruangan atau bilik, sedangkan meranggas memiliki arti keadaan yang gersang. Diksi yang digunakan oleh penyair pada baris pertama mengungkapkan tentang manusia atau kehidupan yang mulai tak berdaya, tidak berenergi karena keadaan atau situasi alam dan juga dipengaruhi oleh perbuatan manusia itu sendiri. Hal ini disaksikan oleh penyair dari tempat di mana ia menjalani hari-hari hidupnya. Ditegaskan pada baris ke dua daun-daunnya gugur menjamak/artinya banyak orang yang telah kehilangan harapan. Tidak hanya satau orang, tetapi dalam jumlah yang banyak di mana penyair menggunakan diksi menjamak yang berarti lebih dari satu.

Pada baris ke tiga Langit pun makin kosong/ Langit menggambarkan tentang kondisi tertinggi atau puncak dari kehidupan yang ideal, tentram, nyaman, kesejahteraan. Tetapi jika dibubuhkan lagi dengan diksi kosong maka memiliki makna tentang kehidupan yang tidak memiliki arti. Manusia tidak menghargai kehidupan yang telah dianugerahkan Tuhan.

Baris ke empat Ketika awan gugur dalam gosong/awan diibartkan seperti gumpalan darah yang menyerupai jabang bayi, awan gugur dan gosong memiliki arti gumpalan darah 
yang sedang menyerupai jabang bayi telah 'lahir' (terpaksa) sebelum waktunya sehingga keadaannya sangat mengenaskan. Manusia telah melakukan aborsi/menggugurkan bayi yang tak bersalah. Perbuatan tersebut telah dilakukan oleh banyak manusia seperti yang lukiskan oleh penyair pada baris 8 dan 9 Jutaan bayi tak genap usia/ Ramai-ramai berganti rahim/. Bayi yang seharusnya berada dalam rahim ibu selama sembilan bulan kini harus mendiami rahim lain. Rahim yang sesungguhnya bukan tempat yang layak bagi bayi (janin).

Siapa yang memaksa? Pastinya mereka yang memiliki awan tersebut. Awan diibaratkan seperti manusia yang terbentuk dari segumpal darah yang tak terhingga berapa banyak gumpalan darah yang terdapat pada diri manusia tersebut. Gumpalan darah itu bersatu hingga terbentuk wujud manusia yang begitu sempurna.

Penyair bergumam Wahai musim gugur!/Kapankah kau berganti semi? karena ia prihatin dengan realita kehidupan yang amat tragis, di mana perbuatan aborsi masi saja terjadi di negeri ini. Hal ini dibuktikan dengan diksi Bumi ini makin merah/. Bumi sebagai tempat berlangsungya kehidupan bagi manusia yang kini telah diwarnai oleh merah yang merupakan warna darah dari bayi korban aborsi.

\section{Pengimajian}

Pengimajian artinya kata atau susunan kata-kata yang dapat mengungkapkan pengalaman sensorik, seperti penglihatan, pendengaran, dan perasaan. Baris atau bait puisi seolah mengandung gema suara (imaji audutif), benda yang nampak (imaji visual), atau sesuatu yang dapat kita rasakan, rabah atau sentuh (imaji taktil). John Dami Mukese dalam puisi "Musim Gugur" menggunakan pengimajian visual. Pengimajian visual yaitu citraan yang ditimbulkan oleh indera penglihatan (mata), Laila (2016). Pengimajian visual dapat dilihat pada baris 1 ketapang depan kamarku kian meranggas/ artinya melihat pohon ketapang yang mulai kering dan daunnya gugur. Pada baris 2 Daun-daunnya gugur menjamak/artinya banyak daun yang jatuh atau gugur. Baris 4 Ketika awan gugur dalam gosong/ awan gugur artinya kelompok butiran air, es, atau kedua-duanya yang tampak mengelompok di atmosfer, pembaca melihat awan jatuh. Awan yang dimaksud penyair adalah bayi atau janin. Pada baris 12 Bumi ini makin merah/merah yang artinya warna dasar yang serupa dengan warnah darah. Pembaca melihat darah yang disandingkan dengan diksi merah.

\section{Gaya bahasa}

Gaya bahasa (stilistika) adalah satu unsur karya sastra yang diperoleh melalui cara penyusunan bahasa sehingga menimbulkan aspek estetis, Ratna (2013). Puisi "Musim Gugur" karya John Dami Mukese mengandung gaya bahasa yang dapat dilihat pada baris 10 dan 11 Wahai musim gugur!/Kapankah kau berganti semi?/ mengandung gaya bahasa perbandingan secara khusus majas personifikasi. Artinya penyair berseru kepada musim gugur yang seolah-olah manusia dan manusia itu dapat menentukan waktu untuk berubah. Seperti musim semi di mana bunga-bunga mulai bermekar. Ada juga gaya bahasa repetisi pada kata gugur yang digunakan secara berulang pada baris 2, 3, 5, dan 10 mengandung makna bayi yang lahir sebelum waktunya. Penyair mau menegaskan tentang perbuatan tidak terpuji yang dilakukan oleh manusia. Gaya bahasa repetisi terdapat pada penggunaan kata tak secara berulang dalam bari 8, 13, dan 14 yang mempunyai arti tidak. 


\section{Rima}

Rima menurut Citraningrum (2014) adalah persamaan bunyi yang berulang-ulang baik pada akhir baris, awal, atau tengah yang tujuannya adalah untuk menumbuhkan efek keindahan. Rima menurut tempat ada rima aawal, tengah, akhir, sempurna, tak sempurna, kakafoni, efoni, aliterasi, asonansi, dan sebagainya, Wisang (2014). Puisi "Musim Gugur" karya John Dami Mukese mengandung rima kakafoni, yang mana penggunaan bunyi konsonan tak bersuara seperti k/p/t/s/ yang menimbulkan kesan atau suasana tertekan, sedih, ngeri. Suasana yang dialami oleh penyair ketika melihat kenyataan yang terjadi. Sebuah perbuatan tidak berperikemanusiaan dalam kehidupan dengan melakukan tindakan aborsi. Rima eufoni digunakan untuk mempertegas suasana dan makna dalam puisi yang terdapat pada baris 3 dan 4 Langit pun makin kosong/ Ketika awan gugur dalam gosong/ serta pada baris 12 dan 13 Bumi ini makin merah/ Oleh darah tak bersalah/. Rima asonansi terdapat pada baris 1 dan 2 Ketapang depan kamarku kian meranggas/ Daundaunnya gugur menjamak/.

\section{Tipografi}

Tipografi disebut juga tata wajah atau perwajahan puisi. Tipografi akan menampilkan aspek artistik visual dan menciptakan nuansa makna dan suasana tertentu. Tipografi juga berperan menunjukkan adanya loncatan gagasan serta memperjelas adanya satuan-satuan makna tertentu yang ingin dikemukakan penyair, Wisang (2014).

Puisi "Musim Gugur" karya John Dami Mukese terdiri atas satu bait, 14 baris yang disusun secara konvensional. Menggunakan huruf kapital pada tiap awal baris 1-12 dan awal baris 13 dan 14 menggunakan huruf kecil, sedangkan tanda baca yang digunakan adalah tanda seruh (!) pada baris 10 dan 14 dan tanda tanya (?) pada baris 11.

\section{Struktur Batin}

\section{Tema}

Tema merupakan gagasan pokok (subject-matter) yang dikemukakan oleh penyair melalui puisinya. Tema haruslah sesuai dengan judul yang menggambarkan ide dan makna yang diangkat (Waluyo dalam Kamila dkk, 2016). Pembaca harus mengetahui latar belakang pengarang atau sosiologi pengarang agar mampu menafsirkan puisi tersebut.

Tema umum dalam puisi "Musim Gugur" karya John Dami Mukese adalah tema tentang kehidupan. Realita kehidupan yang perlu dirubah agar menjadi lebih bermoral, yakni manusia tidak lagi melakukan tindakan aborsi yang dapat dilihat pada kutipan Jutaan bayi tak genap usia/ Ramai-ramai berganti rahim/. Musim gugur sebagai simbol matinya harapan untuk hidup. Manusia (bayi) yang seharusnya memiliki kesempatan untuk hidup, secara terpaksa dibatasi oleh sesama manusia melalui perbuatan aborsi. Realitas atas kehidupan manusia yang kehilangan akan harapan untuk hidup.

\section{Rasa}

Feeling (rasa) ialah sikap penyair terhadap subject matter yang terdapat dalam puisinya. Wirawan (2016). Pengungkapan tema puisi oleh pengarang berkaitan erat dengan latar belakang sosial dan juga psikologi pengarang, misalnya latar belakang pendidikan, pengetahuan, pekerjaan, pengalaman, agama, jenis kelamin, lingkungan sosial, kelas sosial, maupun psikologis. 
Sikap penyair dalam puisi "Musim Gugur" ia merasa marah dan prihatin terhadap manusia yang melakukan aborsi. Sikap marah penyair dibuktikan pada kutipan /bumi ini makin merah/ artinya bumi sebagai tempat makhluk hidup secara khusus manusia hidup dan melangsungkan kehidupannya dipenuhi oleh perbuatan yang tidak bertanggungjawab. Sedangkan diksi merah memiliki arti secara denotasi warna yang beraura kuat, memberi energi untuk menyerukan terlaksananya suatu tindakan. Merah dalam puisi tersebut melambangkan warna darah korban aborsi.

Nada

Nada (tone) merupakan sikap emosional penyair yang dihadirkan dalam karya sastra (Gunatama dalam Kamila dkk, 2016). Nada memiliki keterkaitan dengan tema dan rasa. Pengarang dapat menyampaikan tema dengan nada menggurui, sedih, gembira, dll bergantung pada kondisi pengarang dan realita kehidupan yang mempengaruhi pengarang dalam menciptakan puisi.

Penyair John Dami Mukese merasa sedih terhadap perbuatan aborsi yang dilakukan oleh orang-orang yang tidak memiliki rasa tanggung jawab terhadap perbuatannya. Aborsi terjadi karena kehamilan yang tidak dikehendaki, tindakan tidak manusiawi yang dilakukan secara sadar.

\section{Amanat}

Amanat/tujuan merupakan hal yang mendorong penyair untuk menciptakan puisinya (Waluyo dalam Kamila dkk, 2016). Tujuan tersebut telah direncanakan oleh pengarang sebelum puisi tersebut diciptakan. Amanat yang disampaikan pengarang bisa secara tersurat maupun tersirat.

Amanat yang disampaikan penyair kepada pembaca yakni manusia harus menjaga dan merawat hidup yang telah dianugerahkan Tuhan. Bertanggungjawab terhadap perbuatannya, harus menerima kenyataan, dan bertobat. Siap menerima dampak dari perbuatan yang dilakukan. Artinya manusia tidak lagi melakukan perbuatan-perbuatan tidak terpuji yang tersirat dalam baris 14 akibat dosa tak kenal tobat!/. Mari kita bertobat dengan menjalani hidup yang layak dan pantas.

\section{Relevansi Struktur Puisi "Musim Gugur" Karya John Dami Mukese dengan Pembelajaran Sastra di SMA}

Apresiasi terhadap karya sastra dapat dilakukan melalui berbagi bentuk kegiatan, salah satunya melalui pembelajaran sastra di sekolah. Pengajaran sastra di Sekolah Menengah Atas/Kejuruan pada dasarnya bertujuan agar siswa memiliki rasa peka terhadap karya sastra yang berharga sehingga merasa terdorong dan tertarik untuk membacanya. Mengapresiasi puisi berarti kesanggupan dalam mengenal, memahami, mengharagai, menilai, dan memberi makna terhadap puisi yang dibaca. Setelah melalui tahap apresiasi siswa diharapkan mampu mengimplementasinya dalam kehidupan. Hal yang perlu diiplementasikan seperti yang disampaikan penyair melalui pesan atau amanat dalam puisi yang diciptakan.

Materi tentang struktur puisi yang diajarkan pada pembelajaran sastra tingkat SMA terdapat pada KD. 3.17 menganalisis unsur pembangun puisi. Unsur-unsur pembangun puisi diksi; imaji; kata konkret; gaya bahasa; rima/irama; tipografi; tema/makna (sense); rasa (feeling); dan nada. 
Dalam pembelajaran sastra di sekolah secara khusus pada materi tentang unsurunsur pembangun puisi, guru harus mampu menciptakan pembelajaran yang menyenangkan. Karena dengan cara seperti itulah yang dapat meningkatkan antusiasme siswa. Oleh karena itu, guru dapat memanfaatkan puisi "Musim Gugur" karya John Dami Mukese sebagai salah satu materi pembelajaran pada KD 3.17 tentang unsur-unsur pembangun puisi.

Hasil penelitian ini memiliki relevansi dengan penelitian terdahulu yang dilakukan oleh Hamid dan Dede (2019). Hasil penelitian yang dilakukan oleh Hamid dan Dede (2019) dari analisis struktur puisi-puisi yang terpilih pada majalah Horison. Kedua penelitian memiliki kesamaan yakni menganalisis struktur puisi yang dapat dimanfaatkan oleh guru Bahasa Indonesia sebagai materi ajar dalam pembelajaran sastra secara khusus materi puisi pada jenjang SMA kelas $X$.

\section{Kesimpulan}

Struktur pembangun pusi yang terdiri atas struktur fisik berupa: diksi konotatif dan denotatif; pengimajian visual; kata konkret; gaya bahasa personifikasi dan repetisi; rima kakafoni, eufoni, dan asonansi; dan tipografi yang terdiri atas satu bait, 14 baris dan disusun secara konvensional. Struktur batin berupa tema; feeling (rasa); nada; dan amanat. Struktur pembangun pusi "Musim Gugur" karya John Dami Mukese memiliki relevansi dengan pembelajaran sastra di SMA.

Hasil penelitian ini dapat digunakan sebagai pertama salah satu materi ajar pada pembelajaran sastra KD 3.17 menganalisis unsur-unsur pembangun puisi, kedua melakukan penelitian lanjutan dalam puisi-puisi karya John Dami Mukese, dan ketiga mengembangkan penelitian pembelajaran sastra.

\section{Daftar Pustaka}

Citraningrum, D. M. (2014). Pengantar Apresiasi Sastra. Jember: CV. Cahaya Ilmu.

Hamid, D. A., \& Dede, E. M.(2019). Kajian Puisi dan Pemanfaatannya Sebagai Bahan Ajar Teks Puisi Berbasis Pendekatan Inkuiri. Jurnal Tuturan. Vol. 8 No. 1. 11-18.

Kamila, S., Gede G., \& Ida, B. S. (2016). Puisi Siswa Kelas VIII A MTS Al-Khairiyah Tegalinggah: Sebuah Analisis Struktur Fisik dan Batin Puisi. e-Journal JPBSI Universitas Pendidikan Ganesha. Vol. 4 No. 2.

Laila, A. (2016). Gaya Bahasa Perbandingan dalam Kmpulan Puisi Melihat Api Bekerja Karya M Aan Mansyur (Tinjauan Stilistika). Jurnal Gramatika. Vol. 2 No. 2. 146-163.

Moleong, L. J. (2013). Metodologi Penelitian Kualitatif. Bandung: PT Remaja Rosdakarya.

Nurhuda, T.A., Waluyo, H.J., \& Suyitno. (2017). Kajian Sosiologi Sastra dan Pendidikan Karakter dalam Novel Simple Miracles karya Ayu Utami serta Relevansinya pada Pembelajaran Sastra di SMA. Jurnal Ilmiah DIDATIKA. Vol. 18. No 1. 103-117.

Ratna, N. K. (2013). Glosarium: 1.250 Entri Kajian Sastra, Seni, dan Sosial Budaya. Yogyakarta: Pustaka Pelajar. 
Sehandi, Y. (2018). Penyair John Dami Mukese di Panggung Sastra. http://yohanessehandi.blogspot.com/2018/04/penyair-john-dami-mukese-dipanggung.html

Wirawan, G. (2016). Analisis Struktur Antologi Puisi Hujan Lolos Di Sela Jari Karya Yudhiswara. Jurnal Pendidikan Bahasa dan Sastra Indonesia. Vol. 1. No. 2 September 2016. E-ISSN: 2477-846X. 39-44

Wisang, I. O. (2014). Memahami Puisi dari Apresiasi menuju Kajian. Yogyakarta: Ombak.

Wiyatmi. (2012). Kritik Sastra Feminis: Teori dan Aplikasinya dalam Sastra Indonesia. Yogyakarta: Ombak. 